\title{
XXXVII. On the action of hyponitric acid upon aqueous solutions of bromine and chlorine
}

\section{Dr. C.F. Schœnbein}

To cite this article: Dr. C.F. Schœnbein (1846) XXXVII. On the action of hyponitric acid upon aqueous solutions of bromine and chlorine, Philosophical Magazine Series 3, 29:193, 227-229, DOI: $10.1080 / 14786444608645615$

To link to this article: http://dx.doi.org/10.1080/14786444608645615

Published online: 30 Apr 2009.

Submit your article to this journal $₫$

Џ Article views: 2

Q View related articles $\square$ 
and make $<\mathrm{R}^{\prime} \mathrm{O} \mathrm{P}^{\prime}=<\mathrm{ROP}$, and $<\mathrm{R}^{\prime} \mathrm{OQ}^{\prime}=<\mathrm{ROQ}$. In the directions $O P^{\prime}, O Q^{\prime}$ and $O R^{\prime}$, apply the forces $\mathbf{P}^{\prime}, \mathbf{Q}^{\prime}$ and $\mathbf{R}^{\prime}$ equal to $\mathbf{P}, \mathbf{Q}$ and $R$ respectively; these six forces will, as before, be in equilibrium, and $R$ and $R^{\prime}$ being equal and opposite may be removed; and hence $P, P^{\prime}, Q$ and $\mathrm{Q}^{t}$ will balance each other. Now since

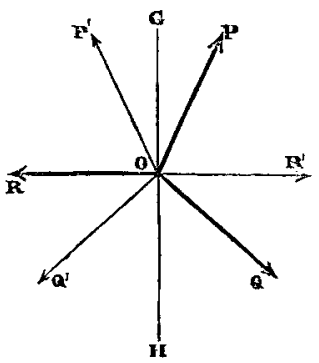

$$
<\mathrm{POH}=<\mathrm{P}^{\prime} \mathrm{OH}=\frac{3 \pi}{2}-\beta,
$$

and

$$
<\mathrm{QOG}=<\mathrm{Q}^{\prime} \mathrm{OG}=\frac{3 \pi}{2}-\alpha,
$$

the resultant of the equal forces

$$
\mathrm{P} \text { and } \mathrm{P}^{\prime}=2 \mathrm{P} . \Phi\left(\frac{3 \pi}{2}-\beta\right) \text {, }
$$

and that of $Q$ and $Q^{\prime}=2 Q . \phi\left(\frac{3 \pi}{2}-\alpha\right)$;

hence, as there is equilibrium, we must have

$$
\begin{gathered}
2 \mathrm{P} \cdot \phi\left(\frac{3 \pi}{2}-\beta\right)=2 \mathrm{Q} \cdot \phi\left(\frac{3 \pi}{2}-\alpha\right) ; \\
\therefore \frac{\mathrm{P}}{\Phi\left(\frac{3 \pi}{2}-\alpha\right)}=\frac{\mathrm{Q}}{\phi\left(\frac{3 \pi}{2}-\beta\right)} ;
\end{gathered}
$$

similarly, it is found that

$$
\begin{gathered}
\frac{\mathrm{Q}}{\phi\left(\frac{3 \pi}{2}-\beta\right)}=\frac{\mathrm{R}}{\phi\left(\frac{3 \pi}{2}-\gamma\right)}, \\
\therefore \frac{\mathrm{P}}{\phi\left(\frac{3 \pi}{2}-\alpha\right)}=\frac{\mathrm{Q}}{\Phi\left(\frac{3 \pi}{2}-\beta\right)}=\frac{\mathrm{R}}{\phi\left(\frac{3 \pi}{2}-\gamma\right)} .
\end{gathered}
$$

Since $\phi \alpha=-\cos \alpha$, this agrees with (17.).

XXXVII. On the Action of Hyponitric Acid upon Aqueous Solutions of Bromine and Chlorine. By Dr. C. F. SchanBEIN*.

THE hydrobromic and hydrochloric acids being decomposed by nitric acid into water, hyponitric acid and romine or chlorine, it appears little likely that by the com1846.

* Communicated by the Chemical Society; having been read April 6, 


\section{Dr. Schœnbein on the Action of Hyponitric Acid.}

bined action of bromine and hyponitric acid water will be decomposed, and the hydrobromic and nitric acids formed. Such however seems to be the case, as will be seen from the following statements.

1. If the fumes of hyponitric acid are made to pass into an aqueous solution of bromine, the brown yellow colour of that fluid will be soon discharged, and its odour of bromine as well as its bleaching power destroyed. The same solution on being mixed either with chlorine or peroxide of lead reassumes its former colour, bromine being eliminated under those circumstances. It is hardly necessary to add, that an aqueous solution of bromine is also discoloured by nitric acid holding some hyponitric acid dissolved. Having added to aqueous bromine a sufficient quantity of hyponitric acid, the liquid obtained contains no trace either of bromine or hyponitric acid, and is in every respect like a mixture of dilute nitric and hydrobromic acids. From the facts stated, it appears that at the common temperature bromine and hyponitric acid on their being put in contact with water are transformed into hydrobromic and nitric acids, and according to the theory of the day, we must account for that reaction by admitting that water is decomposed under the circumstances mentioned.

2. A yellow aqueous solution of chlorine treated with hyponitric acid in the way indicated under $\S 1$, loses its colour, odour and bleaching power, and has exactly the same properties enjoyed by a mixture of dilute hydrochloric and nitric acids. Hence it follows that hyponitric acid acts upon aqueous chlorine in the same way as it does upon an aqueous solution of bromine.

3. If into a bottle, having previously been charged with hydrochloric acid gas, some strong and pure nitric acid is introduced, the latter will, even at a temperature of $15^{\circ} \mathbf{R}$. below zero, be rapidly decomposed, chlorine and hyponitric acid being eliminated and water formed. Adding to that mixture a sufficient quantity of water, both chlorine and hyponitric acid will entirely disappear, i.e. hydrochloric and nitric acids be reformed.

From the facts above stated, it follows,-

$a$. That concentrated nitric and hydrochloric acids decompose each other into hyponitric acid, chlorine and water, even at very low temperatures.

$b$. That a sufficient quantity of water being present, chlorine or bromine, conjointly with hyponitric acid, decompose water (according to the theory of the day), forming nitric and hydrochloric or hydrobromic acid. 
c. That nitric and hydrochloric or hydrobromic acid being dissolved in a sufficient quantity of water, can at the common temperature coexist without decomposing each other.

\section{Notices respecting Nero Boolss.}

Elements of Physics. By C. F. PescheL, Principal of the Royal Military Academy at Dresden. Translated from the German, with notes, by $\mathrm{E}$. WEST. 3 vols. foolscap octavo.

7 HIS is a work of great merit. It contains a condensed account 1 of almost every branch of the extensive subject on which it treats, with the most approved formulæ, conveniently arranged, for computing in every department, and it is copiously illustrated with woodcuts.

The first volume treats of the properties of ponderable bodies,-mass, density, attraction, motion, mechanical and chemical action, \&c. ; the construction of machines, the laws of force, the theory of undulation, and a multitude of other subjects connected with matter having sensible weight, and all discussed with an ability which leaves little to be desired in a work which, though essentialiy scientific, is yet decidedly popular.

We should have been glad to see from the author, or the translator, a chapter on the measurement of heights from the temperature of boiling water, a subject which we think has not received the attention which it is entitled to.

The second and third volumes, that of imponderable bodies-light, heat, electricity, magnetism, \&c.; and here again we trace the hand of a master, who has placed before his readers, in the most lucid order, those branches of science in their modern improved state.

The work is a little encyclopædia of physical science, and we heartily recommend it as a work by which the public will benefit.

\section{Proceedings of Learned Societies. ROYAL ASTRONOMICAL SOCIETY.}

[Continued from p. 144.]

Ancient Eclipses of the Sun, computed by M. Rumker.

May 8, W HEISS, of Cologne, has calculated the particulars 1846. W1. of two eclipses during the Peloponnesian war which are mentioned in history, viz. one on August 3,431 A.c., and another on March 21, 424 A.c.

M. Rumker has given the particulars of four more, in the hope that they may have been noticed by some ancient writer:-

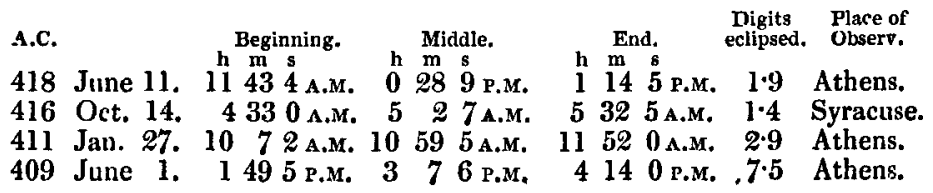

